\title{
PADRÃO DE QUALIDADE DE CACHAÇAS PRODUZIDAS NO VALE DO MUCURI - MG NO ANO DE 2019
}

\section{QUALITY STANDARD OF CACHAÇAS PRODUCED IN THE VALE DO MUCURI - MG IN 2019}

\section{Bryan Santos Coutinho}

Acadêmico do $9^{\circ}$ Período do Curso de Farmácia da Faculdade Presidente Antônio Carlos - UNIPAC Teófilo Otoni-MG. bryansantos_asp@ hotmail.com

Gabriel Sampaio Barbosa

Acadêmico do $9^{\circ}$ Período do Curso de Farmácia da Faculdade Presidente Antônio Carlos - UNIPAC Teófilo Otoni-MG. gabybarbosa06@ hotmail.com

Daniel de Azevedo Teixeira Doutorado em Biocombustíveis- Coordenador do curso de Farmácia da UNIPAC de Teófilo Otoni. danielteixeira@unipacto.com.br

\author{
Lucio Onofri \\ Mestrado em Zootecnia. Docente do curso de Farmácia da UNIPAC de Teófilo \\ Otoni \\ E-mail: $\underline{\text { lucioonofri@gmail.com }}$
}

\begin{abstract}
Resumo
A cachaça é uma bebida tipicamente brasileira, sendo o segundo produto alcoólico mais consumido no país. Este estudo teve como objetivo analisar amostras de 10 cachaças distintas produzidas e comercializadas na região do Vale do Mucuri-Minas Gerais. Os destilados foram analisados quanto às suas propriedades organolépticas, e por meio de procedimentos físico-químicos, foram submetidos à análise para determinação do padrão de qualidade em relação a compostos secundários. Os resultados obtidos foram comparados com o texto legal que regulamenta os parâmetros de qualidade para as aguardentes de cana. Das amostras analisadas os parâmetros com menores índices de reprovação foram furfural, metanol e congêneres, ambos apresentando conformidade em $80 \%$ das cachaças. O teor alcoólico encontrado na bebida e a sua correspondência com a graduação alcoólica expressa no rótulo ocorreu também em $80 \%$ das amostras. $\mathrm{O}$ cobre apresentou valores inadequados em $40 \%$ das aguardentes de cana analisadas e os níveis de Ésteres e Acidez volátil apresentaram-se adequados em $70 \%$ das bebidas.
\end{abstract}

Palavras-chave: Cachaça; Padrões de qualidade; análise; bebida alcoólica 


\begin{abstract}
The cachaça is a typical Brazilian drink, it is the second alcohol product most consumed in the country. This research aimed to analyse 10 distinct cachaças's samples produced and marketed in the region of Vale do Mucuri - Minas Gerais. The liquors were analysed with its organoleptic properties, and by means of physicochemical procedures, they were analysed in order to determination of quality standards related to the secondary compounds. The results achieved were compared with the legal regulation, which regulates the quality parameters of liquor from sugarcane. Of all samples analysed, the parameters with less disapproval indices were furfural, methanol and related, both presented compliance in $80 \%$ of the samples. The alcohol content in the drink and its conformity with the alcohol levels expressed in the label occurred in $80 \%$ of the samples. The copper presented inadequate values in $40 \%$ of the sugarcane drinks analysed and the Ester and volatile Acidity levels presented were appropriate in $70 \%$ of it.
\end{abstract}

Keywords: Cachaça; Quality Standards; Analyses; Alcoholic beverage

\title{
1 INTRODUÇÃO
}

Existem diversas versões sobre a invenção da cachaça no Brasil, mas fato é que sua história se iniciou com a introdução da cana de açúcar originaria da Ásia na agricultura do Brasil pelos colonizadores portugueses, e desenvolveu-se junto à agroindústria da cana de açúcar que abastecia o império português. O consumo da bebida foi inicialmente feito pelos negros escravizados que trabalhavam na produção de cana de açúcar e nos engenhos, onde os restos da produção do açúcar fermentado eram oferecidos aos mesmos como uma espécie de energético.

Com o advento da mineração no estado de Minas gerais o consumo da cachaça se expande para o interior e passa a fazer parte do cardápio da população local, chegando inclusive à mesa dos senhores de escravos. Seu largo crescimento passou a fazer frente a importação de vinho e da bagaceira portuguesa, levando a coroa portuguesa a intervir com proibições e taxação da bebida numa tentativa de frear seu consumo e reestabelecer a força da importação de bebidas portuguesas (SILVA, et al; 2006).

Tais esforços se mostraram inúteis pois a cachaça, muito mais barata e acessível, passou a representar uma forma de resistência ao império português, sendo seu consumo 
algo simbólico durante o movimento da Inconfidência Mineira que rechaçava o vinho português por achar seu consumo algo não patriótico. No entanto, tal popularização somada a não planejada abolição da escravatura que lançou milhares de escravos, os principais consumidores da cachaça, às ruas sem meios de se prover, criou uma associação do uso da bebia com a miséria e a vagabundagem. Promovendo um estigma ainda hoje bastante associado ao consumo da cachaça. Na contramão da submissão à cultura europeia que imperava no Brasil, a Semana da Arte Moderna, em 1922, promoveu a valorização da cultura nacional e veio resgatar o valor simbólico da cachaça como uma bebida genuinamente brasileira (SILVA, et al; 2006).

Desde então a cachaça tem crescido em sua importância cultural, histórica e econômica, sendo em 2005 reconhecida como um produto exclusivo do Brasil (BRAGA; KYOTANI, 2015). Em função de sua importância turística, cultural e econômica, em certas regiões do Brasil a cachaça tem recebido diversos títulos de reconhecimento do seu valor cultural, ou histórico. Um exemplo relevante é o reconhecimento da cachaça, por meio de lei do estado do Rio de Janeiro, como patrimônio histórico cultural desde 2007 e o recebimento do título de patrimônio cultural imaterial da cidade de Salinas, na região norte do estado de Minas Gerais, desde 2006 (BRAGA; KYOTANI, 2015). A cidade não só reconhece a importância da cachaça para a região como se vale de sua fama como 'Terra da Cachaça' para impulsionar o turismo e a economia local, tendo sido reconhecida pela lei federal 13.773 de 19 de dezembro de 2018 como a Capital Nacional da Cachaça.

Tal reconhecimento é reflexo do impacto do agronegócio da cachaça na economia brasileira. Pois é a segunda bebida mais consumida no país, e o terceiro destilado mais consumido no mundo, com produção anual cerca de 1,3 bilhão de litros de cachaça (SILVA et al., 2013 apud ESTANISLAU et. al., 2002). Apresentando apenas $0,08 \%$ de sua produção destinada à exportação (Silva et al apud MIDC, 2006). Em Minas Gerais a produção da Genuína cachaça mineira gera cerca de $R \$ 1,4$ bilhão por ano, o que afeta positivamente a economia das regiões onde se situam os 8.466 estabelecimentos produtores do estado. Destes, $53 \%$ concentram-se nas mesorregiões do Norte de Minas, Vale do Jequitinhonha, e Vale do Mucuri (CAMPELO, 2002 apud 
Silva et al). Sendo as cachaças produzidas nessa última região o objeto de estudo deste trabalho. Estes dados apontam o forte potencial econômico, e de produção destas regiões, visto que mesmo frente as graves condições socioeconômicas são responsáveis pela maior parte da produção do estado. Mas dentro deste contexto, há que se destacar que $85 \%$ não possuem registro no Ministério da Agricultura, Pecuária e Abastecimento que certifique as caraterísticas que determinam o padrão de qualidade da cachaça (CAMPELO, 2002 apud SILVA et al).

Existem algumas regulamentações que estabelecem o padrão de qualidade da cachaça e a diferenciam da aguardente de cana. O Decreto $n^{\circ} 4851 / 2003$ e a Instrução Normativa n 13/2005 do Ministério da Agricultura, Pecuária e Abastecimento definem a aguardente de cana como:

Bebida com graduação alcoólica de 38 a $54 \%$ v/v à $20{ }^{\circ} \mathrm{C}$, obtida do destilado alcoólico simples de cana-de-açúcar ou pela destilação do mosto fermentado do caldo de cana-de-açúcar, podendo ser adicionada de açúcares até $6 \mathrm{~g} / \mathrm{L}$, expressas em sacarose e definem a cachaça como sendo a denominação típica e exclusiva da aguardente de cana produzida no Brasil, com graduação alcoólica de 38 a $48 \%$ v/v à $20{ }^{\circ} \mathrm{C}$, obtida pela destilação do mosto fermentado do caldo de cana-de-açúcar com características sensoriais peculiares, podendo ser adicionada de açúcares até $6 \mathrm{~g} / \mathrm{l}$, expressos em sacarose (BRASIL,2003)

O que explicita que toda cachaça é uma aguardente de Cana, mas nem toda aguardente de cana se caracteriza como cachaça, em função de seu volume alcoólico superior à $48 \% \mathrm{v} / \mathrm{v}$ à $20^{\circ}$. No entanto, em 2001, a lei estadual $\mathrm{n}^{\circ} 13.949$ define a Cachaça de Minas como sendo:

\footnotetext{
A bebida com graduação alcoólica de $38 \%$ a $54 \%$ v/v, à temperatura de $20^{\circ} \mathrm{C}$, obtida pela destilação do mosto fermentado de cana-de-açúcar, em alambique de cobre, sem adição de açúcar, corante ou outro ingrediente qualquer (MINAS GERAIS, 2001).
}

Normativa que já definia as particularidades da Cachaça de Minas em relação as demais cachaças do país.

As bebidas alcoólicas fermentadas e que posteriormente sofrem um processo de destilação, distinguem-se umas das outras pela presença de componentes secundários que formam um "buquê" característico de cada bebida. Esses compostos secundários se formam juntamente com o etanol durante a fermentação do mosto. Tais compostos mudam de caráter e proporção durante a destilação, ocorrendo uma posterior maturação do produto. Entretanto alguns compostos são inconvenientes à bebida, principalmente 
devido às suas propriedades tóxicas e cancerígenas, o que prejudica a qualidade final do destilado. (ALMEIDA, et al, 1971).

A cachaça é um produto de representatividade nacional e se faz presente em diversos aspectos da sociedade brasileira. Faz parte da gastronomia, das comemorações, da economia e da tradição do povo brasileiro. Devido a relevância da produção de aguardente de cana para o Vale do Mucuri (MG), é importante saber se o produto dessa região está dentro dos padrões de qualidade exigidos pelas normas nacionais e mineiras. Inúmeras substâncias tóxicas podem ser formadas durante o processo de destilação e armazenamento da bebida, o que pode gerar danos à saúde. Outro ponto importante, e que descaracteriza a cachaça é o seu teor de álcool. A bebida produzida pode conter porcentagem alcoólica superior ou inferior à tradicional, o que compromete o seu sabor. Outro parâmetro a ser analisado é a presença de metanol, um álcool tóxico que pode causar danos à saúde.

Este estudo tem por objetivo analisar parâmetros de qualidade de aguardentes produzidas no Vale do Mucuri, dosando a presença de substâncias tóxicas como o furfural e metanol, a presença de substâncias que comprometem a qualidade do destilado, como o cobre, ésteres e acidez volátil, além do teor alcoólico das bebidas. Para a realização deste estudo, foram coletadas 10 amostras de cachaças produzidas na região do Vale do Mucuri (MG). Essas amostras foram enviadas para laboratório onde elas foram analisadas.

\section{METODOLOGIA}

\subsection{Classificação da pesquisa}

Trata-se de uma pesquisa experimental e quantitativa para a determinação do padrão de qualidade de 10 marcas de cachaças do vale do Mucuri-MG.

\subsection{Procedimento de coleta de dados}


Foram coletadas amostras de cachaças em diferentes cidades do vale do MucuriMG. As amostras foram identificadas com a marca do produto, graduação alcoólica, cidade de produção, data da coleta e número de registro no MAPA. As amostras foram analisas pelo laboratório de análises físico-química da Universidade Federal do Rio Grande do Sul (UFRGS).

\subsection{Teste Organoléptico}

Foram analisados os parâmetros de coloração, aspecto, corpos estranhos e limpidez. O teste organoléptico foi realizado através de transluminador de luz branca.

\subsection{Determinação de Teor alcoólico}

Foram determinados os teores alcoólicos em consonância com a descrição apresentada nos rótulos. A metodologia empregada utilizou densímetro digital como medições a $20{ }^{\circ} \mathrm{C}$.

\subsection{Determinação de Acidez volátil}

Os teores de acidez volátil foram identificados através de titulação volumétrica por neutralidade. Utilizou-se a metodologia de arraste a vapor para a extração dos ácidos voláteis.

\subsection{Determinação de Ésteres}

A determinação dos teores de ésteres ocorreu utilizando a titulação de ácidos carboxílicos através do processo de transesterificação dos ésteres presentes nos produtos. 


\subsection{Determinação dos teores de Aldeídos}

A quantidade de aldeídos presentes nas amostras foi determinada através de titulação volumétrica com iodo $0,05 \mathrm{~mol} / \mathrm{L}$ titulando $\mathrm{SO} 2$ formado por reações envolvidas no meio.

\subsection{Determinação dos teores Furfural}

A presença de furfural foi determinada através de espectrofotometria a $520 \mathrm{~nm}$. As amostras foram destiladas e o grau alcoólico corrigido para 50 GL. Os resultados foram expressos em miligrama de furfural em $100 \mathrm{ml}$ de álcool anidro.

\subsection{Determinação da presença de Metanol}

A presença de metanol foi determinada por espectrofotometria a $520 \mathrm{~nm}$. Os resultados foram expressos em miligrama de metanol em $100 \mathrm{ml}$ de álcool anidro.

\subsection{Determinação dos teores de Congêneres}

A expressão dos resultados de congêneres foi estabelecida através da soma dos resultados de acidez volátil, ésteres, aldeídos, furfural e álcoois superiores.

\subsection{Determinação dos teores de cobre}

A determinação dos teores de cobre foi realizada através de espectrofotometria a $520 \mathrm{~nm}$. Os resultados foram expressos em miligrama de cobre em $100 \mathrm{ml}$ de álcool anidro. 


\section{RESULTADOS E DISCUSSÃO}

\subsection{Determinação os padrões organolépticos das cachaças}

Todas as amostras foram aprovadas nos testes organolépticos, sem qualquer tipo de restrição.

\subsection{Determinação do Teor alcoólico presente em cachaças de acordo com a apresentação em rótulo}

De acordo com dados obtidos verificou-se o teor alcoólico das amostras de cachaças a $20^{\circ} \mathrm{C}$ e sua correspondência com os valores descritos nos rótulos das garrafas. Portanto, foi identificado que $80 \%$ das amostras apresentaram conformidade entre o teor alcoólico das bebidas e o valor expresso nos rótulos. As demais amostras cerca de $20 \%$ das cachaças mostraram-se incompatíveis quanto a sua graduação alcoólica e o valor especificado na sua rotulagem.

Gráfico 1. Determinação de teor alcoólico a $20^{\circ} \mathrm{C}$ em conformidade com os rótulos. 


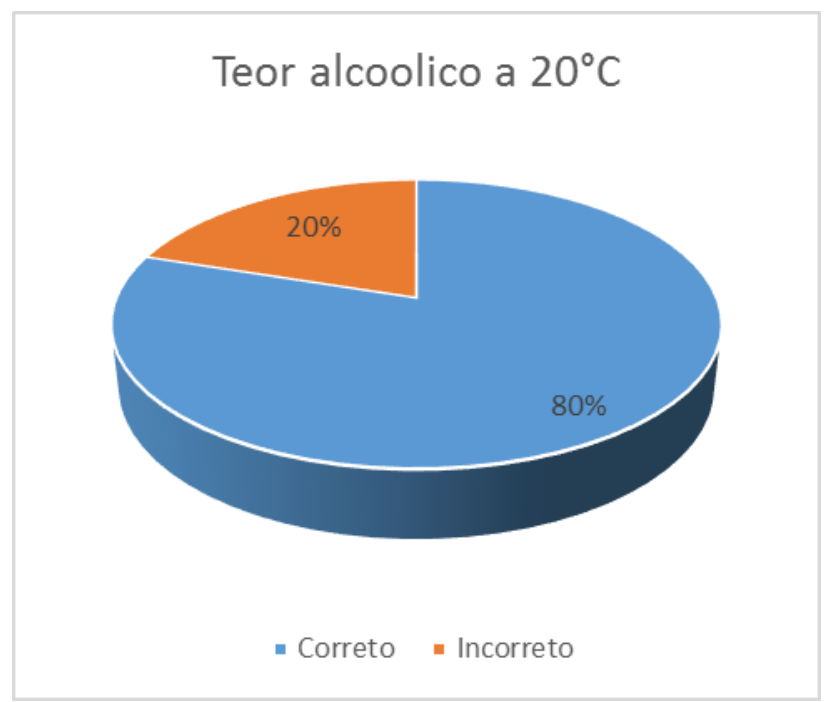

Fonte: Resultados da própria pesquisa 2019

Os resultados obtidos são semelhantes aos valores encontrados por Zacaroni (2011) cujas amostras analisadas apresentaram 25\% de incompatibilidade em relação ao teor alcoólico. De acordo com a instrução normativa $n^{\circ} 13$, de 29 de junho de 2005 cachaça apresenta teor de álcool entre $38 \%$ e $48 \%$ a $20^{\circ} \mathrm{C}$ em volume. Alguns fatores como umidade e temperatura podem ocasionar redução do teor alcoólico das aguardentes.

Os poros da madeira utilizada para o armazenamento da bebida também podem permitir a perda de álcool do destilado (ZACARONI et. al 2011). Essas circunstâncias podem justificar uma incompatibilidade de $20 \%$ em relação ao percentual alcoólico das cachaças do vale do Mucuri analisadas no presente estudo; visto que a região é predominantemente quente e seca.

Estudos feitos por Maia e Campelo (2006) evidenciam que a perda de álcool pode diminuir durante o processo de envelhecimento se a temperatura da adega ficar abaixo de $20^{\circ} \mathrm{C}$ e a umidade do ar em cerca de $85 \%$.

\subsection{Determinação do teor de Furfural presentes nas cachaças analisadas}

Das aguardentes analisadas, a maioria das amostras, 80\% estão dentro dos parâmetros estabelecidos pela legislação brasileira para o teor de furfural, que é de até 
5mg/ 100ml de álcool anidro. E 20\% das amostras analisadas não estão dentro dos limites estabelecidos.

\section{Gráfico 2. Determinação do limite da presença de Furfural.}

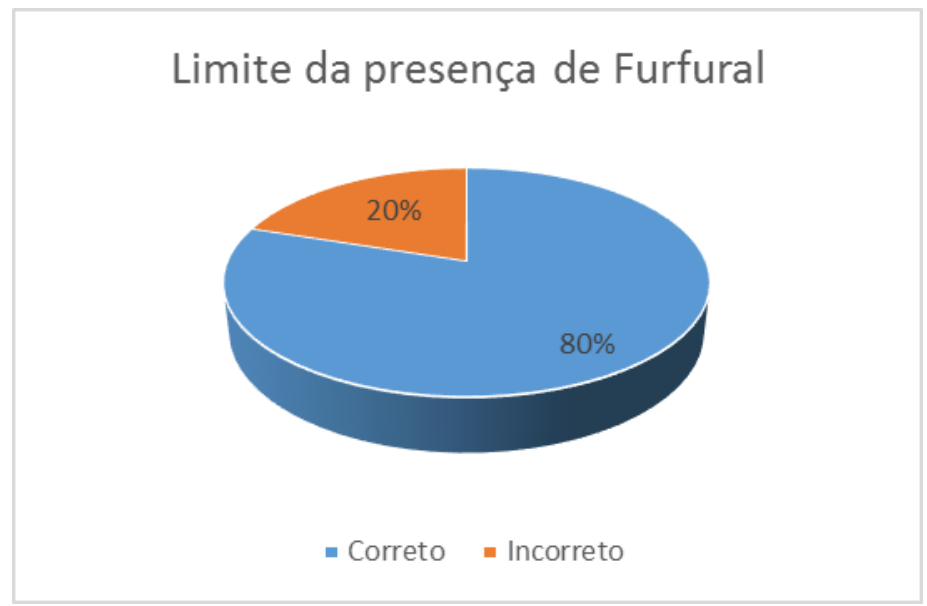

Fonte: Resultados da própria pesquisa 2019

O furfural é uma substância inconveniente nas aguardentes por ser prejudicial à saúde. A presença de furfural no destilado pode se dar pela decomposição das pentoses durante o processo fermentativo, e também nas etapas de destilação e envelhecimento das cachaças. A contaminação por furfural também pode se dar pela queima da cana de açúcar antes da realização da colheita (MORENO, MASSON, et al. 2002, p.50).

Para Maia (1994), o calor aliado ao reduzido pH do mosto provoca desidratação dos açúcares e hidrólise de carboidratos como a celulose, hemicelulose e pectina contidos nos bagacilhos da cana-de-açúcar. O resultado desses processos é a formação do furfural e do 5-hidroximetilfurfural (5-HMF).

O controle da temperatura no decorrer do processo de destilação do mosto, e o descarte da porção denominada cauda, pode contribuir para a redução dos níveis de furfural e 5-HMF (ALCARDE et.al 2014). Portanto, acredita-se que haja necessidade de propor melhor controle na etapa de fervura do mosto.

\subsection{Determinação da Acidez volátil}


O limite estabelecido pela INSTRUÇÃO NORMATIVA N $\mathrm{N}^{\circ}$ 13, DE 29 DE JUNHO DE 2005 para acidez volátil expressa em ácido acético é de $150 \mathrm{mg} / 100 \mathrm{ml}$ de álcool anidro (BRASIL, 2005)

Das amostras analisadas $70 \%$ delas estavam dentro dos parâmetros legais estabelecidos. Apenas 30\% das cachaças avaliadas apresentaram níveis de acidez volátil acima do permitido.

\section{Gráfico 3. Limites de acidez volátil.}

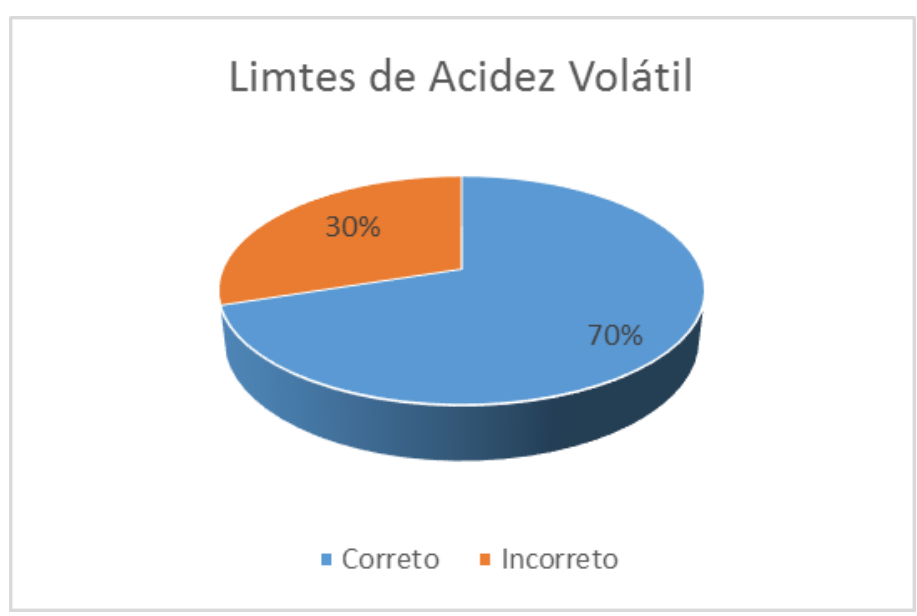

Fonte: Resultados da própria pesquisa 2019

Em aguardentes produzidas no Mato Grosso constatou-se que uma das amostras excedeu os limites legais, apresentando uma concentração de 329,07 mg de ácido acético por $100 \mathrm{ml}$ de álcool anidro (Pellenz et. al 2017).

De acordo com França (2011) de 8 amostras de cachaças distintas, produzidas no município de Passos- MG, constatou-se que 12,5\% das cachaças analisadas não estavam dentro dos valores permitidos para acidez volátil. Sendo que a amostra em questão apresentou valor de $590 \mathrm{mg}$ de ácido acético por $100 \mathrm{ml}$ de álcool anidro, valor bem acima dos $150 \mathrm{mg}$ permitidos pela legislação.

Em um trabalho, Borges (2011) observou incompatibilidade em 27,7 \% das 11 amostras provenientes de diversas regiões da Bahia em relação a acidez volátil. Essas amostras apresentaram valores superiores ao permitido pela legislação. 
Bogusz Júnior e Ketzer (2006) ao analisar 27 cachaças produzidas no Rio Grande do Sul obtiveram duas amostras que apresentaram valores de 185,8 e $180 \mathrm{mg}$ de ácido acético/ $100 \mathrm{ml}$ de álcool anidro. Para eles, esses valores excessivos são provenientes da falta de conhecimento técnico por parte dos produtores das bebidas.

Os elevados níveis de acidez volátil em cachaças podem estar associados à contaminação da cana de açúcar ou do mosto por bactérias acéticas. Em consequência disso uma porção do substrato sofre fermentação acética, o que reduz a produção do álcool etílico e aumenta a acidez da bebida (CARDOSO 2001).

No alambique, as primeiras frações que sofrem destilação apresentam pouca acidez, porém a acidez volta a aumentar na parte final da destilação (RIBEIRO; PRADO-FILHO, 1997).

Para evitar que o destilado apresente níveis elevados de acidez volátil é importante tomar medidas como manter a temperatura adequada, ter boas práticas de higiene durante o processo de produção da bebida e realizar o processo de destilação assim que o mosto estiver pronto, afim de evitar fermentação secundária (SILVA et al., 2003).

\subsection{Determinação da concentração de éster}

Em relação aos ésteres expressos em acetato de etila, $70 \%$ das amostras analisadas neste estudo estão dentro dos valores estabelecidos pela legislação que é de até $200 \mathrm{mg}$ por $100 \mathrm{ml}$ de álcool anidro.

\section{Gráfico 4. Limite de concentração de ésteres.}




\section{Limite da concentração de estéres}

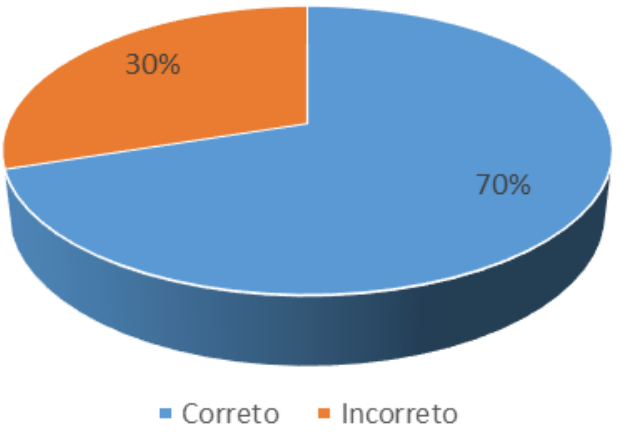

Fonte: Resultados da própria pesquisa 2019

Pellenz,et.al (2017) ao analisar aguardentes produzidas na região Norte do Mato Grosso, constatou que apenas $20 \%$ das amostras estavam dentro dos limites legais quanto a concentração de ésteres. Das cinco amostras analisadas, quatro excederam a concentração de $200 \mathrm{mg}$ de ésteres totais.

Para Parazzi et. al (2008) a formação dos ésteres se dá por meio de reações enzimáticas intracelulares de leveduras durante o processo fermentativo.

Dentre os fatores que influenciam a formação de Ésteres estão a qualidade e o número de leveduras, a temperatura mantida durante o processo de fermentação, além da agitação e do arejamento do mosto. A escassez de nitrogênio e a falta de arejamento podem elevar os níveis de ésteres (JANZANTTI, 2004).

\subsection{Correlação entre acidez volátil e ésteres}

Existe uma correlação entre Acidez volátil e Ésteres. Isso se deve ao fato do ácido acético reagir com o etanol para formar o éster acetato de etila, que corresponde a $80 \%$ dos ésteres da aguardente de cana (Parazzi et. al 2008).

\section{Gráfico 5. Demonstração da Correlação entre ésteres e acidez volátil.}




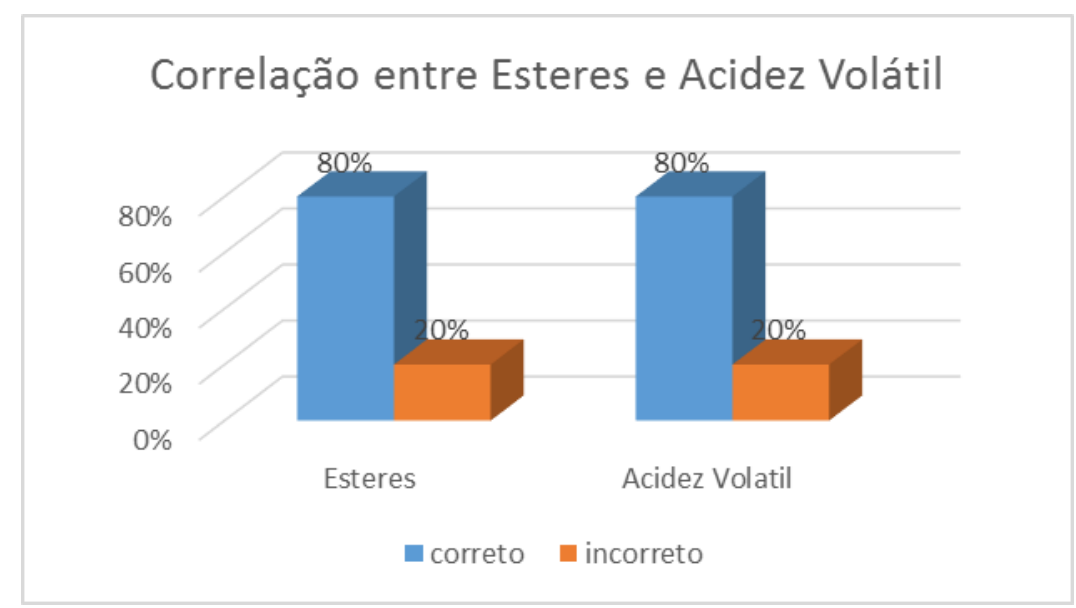

Fonte: Resultados da própria pesquisa 2019

Portanto níveis elevados de acidez volátil podem implicar em níveis elevados de Ésteres. Tal correlação se mostrou evidente neste trabalho, conforme demonstra o gráfico.

\subsection{Limite para congêneres}

De acordo com a instrução normativa $n^{\circ} 13$, de 29 de junho de 2005 do Ministério da Agricultura, congêneres é a soma de ésteres, acidez volátil, aldeídos, álcoois superiores e furfural presentes na cachaça. Os valores para esse parâmetro não podem ser inferiores a $200 \mathrm{mg} / 100 \mathrm{ml}$ e nem podem ser superiores a $650 \mathrm{mg} / 100 \mathrm{ml} \mathrm{de}$ álcool anidro.

Das amostras analisadas neste estudo $20 \%$ não apresentaram valores compatíveis com os permitidos pela legislação. Essa incompatibilidade pode ser justificada pelo fato de outros contaminantes como furfural, Éster e ácido acético também não apresentarem valores adequados nas amostras. Porém a maior parte das amostras, o que equivale a 80\% das aguardentes, apresentam níveis adequados de congêneres, conforme demonstra o gráfico.

\section{Gráfico 6. Limite para congêneres.}




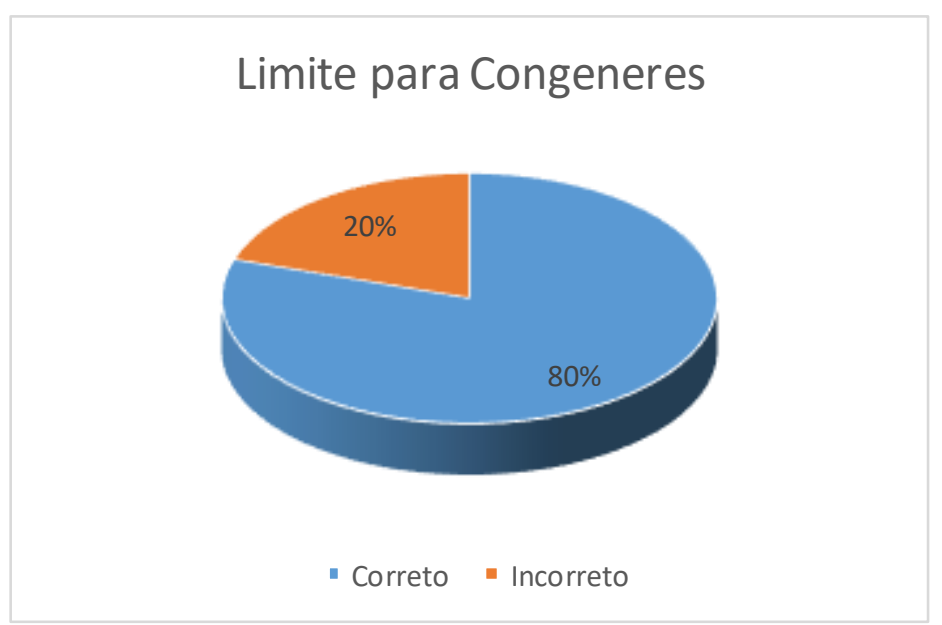

Fonte: Resultados da própria pesquisa 2019

Miranda 2007 ao analisar 94 cachaças produzidas em diversas regiões do Brasil, constatou que $8,51 \%$ das amostras não estavam regulares quanto ao parâmetro congêneres.

\subsection{Determinação do teor de Metanol em Aguardentes de Cana}

Para o contaminante metanol obteve-se $20 \%$ de incompatibilidade entre os níveis permitidos pela legislação e os níveis encontrados nas amostras analisadas. A Instrução Normativa $\mathrm{N}^{\circ} 13$, de 29 de junho de 2005 estabelece que o valor de metanol (álcool metílico) em cachaças, não pode ultrapassar a quantidade de $20 \mathrm{mg} / 100 \mathrm{ml}$ de álcool anidro (BRASIL,2005). As demais amostras, o que equivale a $80 \%$ das bebidas, estavam dentro dos parâmetros legais, e não excederam o valor tolerado.

\section{Gráfico 7. Demonstração da presença de Metanol.}




\section{Limite da presença de Metanol}

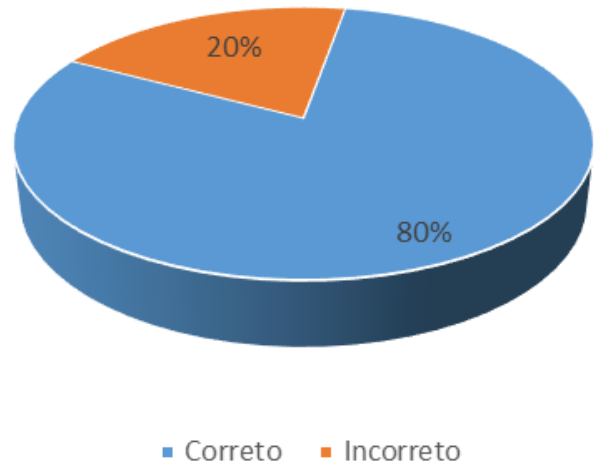

Fonte: Resultados da própria pesquisa 2019

Machado et. al (2016) após análise de 15 amostras de cachaças produzidas no Vale do São Francisco constatou valores excessivos de metanol em $73.3 \%$ das bebidas analisadas. Sendo que o teor de álcool metílico encontrado nas amostras sofreu variação de $33,1 \mathrm{mg}$ a $355,3 \mathrm{mg}$ por $100 \mathrm{ml}$ de álcool anidro. A amostra com maior contaminação excedeu em mais de 17 vezes o nível permitido pela legislação, que é de 20mg/100 ml de álcool anidro.

Em um trabalho com o intuito de verificar a adulteração de diversas bebidas alcoólicas, Nagato (2001) analisou 46 aguardentes de cana de açúcar. Uma dessas cachaças apresentou teor extremamente elevado de metanol $10 \mathrm{~g} / 100 \mathrm{ml}$, o que gerou intoxicação aguda grave na pessoa que a ingeriu, resultando em cegueira.

Caruso (2010) ao analisar 61 amostras de cachaças produzidas em diversas regiões do Brasil, não obteve como resultado nenhuma amostra de cachaça que excedesse o limite legal, apresentando todas concentrações inferiores a $20 \mathrm{mg} / 100 \mathrm{ml}$ de álcool anidro.

Vilela (2007) ao analisar amostras de cachaças de distintas regiões do Sul de Minas Gerais encontrou em algumas bebidas valores ínfimos para álcool metílico, e em outras amostras o contaminante não foi encontrado. 
A presença do álcool metílico na cachaça se dá como produto secundário do processo fermentativo. Quando o metanol é encontrado em pouca quantidade na bebida alcoólica, ele não é um risco à saúde das pessoas (BOGUSZ JUNIOR 2006).

Em contrapartida, para Lamiable (2004) a presença do metanol não é conveniente às bebidas devido a sua toxicidade, podendo provocar dores de cabeça, tontura, êmese, além de dores em diversas partes do corpo. O uso prolongado de bebidas contendo metanol, mesmo que em quantidades pequenas, pode causar cegueira e até mesmo provocar o óbito.

Após ingerido, o metanol sofre oxidação, se transforma em ácido fórmico e depois em Dióxido de Carbono. Isso resulta em elevada acidose e interferência no sistema respiratório (GIUDICI, 1993).

A formação do metanol na aguardente de cana ocorre primordialmente quando não há eficiência ou mesmo inexiste a filtragem dos bagacilhos do caldo da cana durante o processo de moagem. Isso se justifica pelo fato dos bagacilhos terem grande quantidade de pectina (BOGUSZ JUNIOR, 2006).

Para se obter níveis adequados de metanol os bagacilhos da cana de açúcar devem ser removidos utilizando-se peneiras ou decantadores, além disso, deve-se promover a higienização adequada dos destiladores. Outra forma de se evitar valores incompatíveis do metanol é promover a separação adequada da porção denominada cabeça que possui concentrações maiores do álcool metílico (VILELA 2005).

Falhas durante a retirada dos bagacilhos após a moagem, erros durante a separação da porção denominada cabeça e a falta de higienização dos alambiques podem ser a causa da inadequação de $20 \%$ das amostras deste estudo quanto a níveis de metanol. Devido ao fato das cachaças serem produzidas de maneira artesanal e muitas vezes sem a qualificação técnica por parte dos produtores, visto que a região é carente de recursos socioeconômicos, estas bebidas estão mais sujeitas a inadequações em diversos parâmetros.

\subsection{Determinação do Teor de Cobre}


Ao analisar cachaças produzidas no Sul de Minas Gerais (Vilela et. al.) demonstrou que $66,66 \%$ das bebidas estavam com o nível de cobre acima dos $5 \mathrm{mg} / \mathrm{L}$ permitidos pela legislação. Neste estudo realizado com cachaças produzidas no Vale do mucuri, região Nordeste de Minas Gerais constatou-se que 40\% das amostras apresentaram teores de cobre acima do limite legal, e $60 \%$ das amostras estavam dentro dos padrões legais em relação a concentração de Cobre.

\section{Gráfico 8. Demonstração do limite para presença de cobre.}

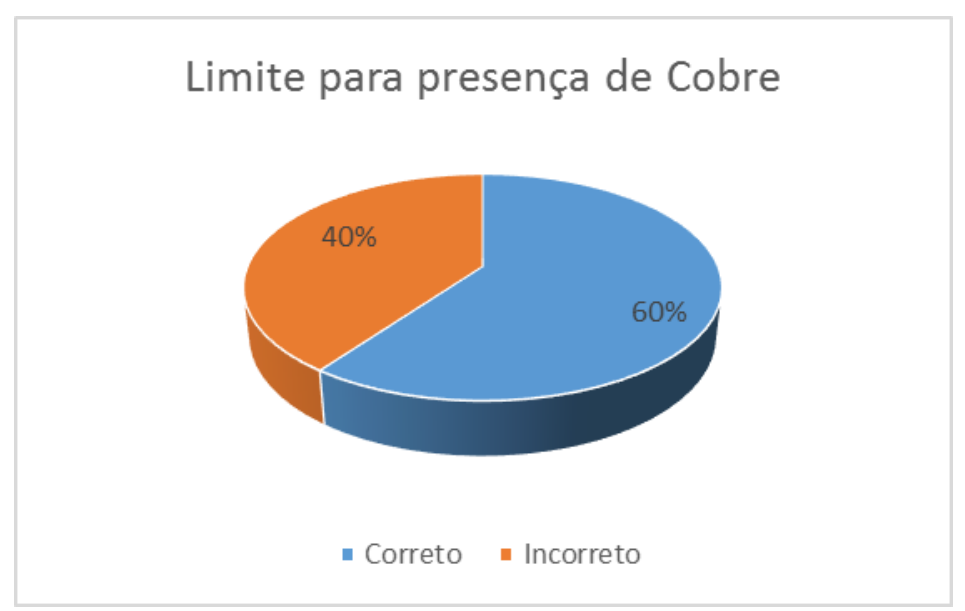

Fonte: Resultados da própria pesquisa 2019

Em uma pesquisa realizada para detectar o teor de Cobre em cachaças produzidas no Vale do Jequitinhonha-MG, (Pinto et. al, 2011) analisou 52 amostras de cachaças distintas. Das 52 aguardentes, um total de 18 amostras ultrapassaram os limites legais permitidos para Cobre, o que equivale a $34,6 \%$ das cachaças. Os resultados obtidos pelo autor se aproximam dos resultados obtidos no presente estudo.

Ao analisar 13 aguardentes oriundas de duas regiões do Maranhão, Mendes Filho (2016) não encontrou excesso do contaminante cobre em nenhuma das amostras.

A cachaça destilada em alambique com materiais de cobre é mais agradável aos sentidos quando comparada à cachaças produzidas em alambiques de outros materiais, como alumínio, porcelana e aço inoxidável. Aguardentes de cana destiladas em alambiques de cobre apresentam menor acidez e índices inferiores de substâncias que 
conferem odor e sabor desagradáveis à bebida como aldeídos e compostos sulfurosos (CARDOSO et. al 2003).

A má higienização dos alambiques é uma das hipóteses para níveis de cobre elevados em cachaças, visto que o cobre é oriundo da dissolução do azinhavre formado dentro destes alambiques (AZEVEDO et. al 2003).

O azinhavre é dissolvido em vapores hidro alcoólicos ácidos e provoca contaminação da cachaça com cobre iônico (LIMA et. al 2006).

Para a remoção do azinhavre que se acumula dentro da serpentina de condensação do alambique, e consequente redução dos níveis de cobre, Cardoso (2006) orienta que diariamente, a primeira destilação seja realizada com suco de limão ou ácido cítrico misturado à água. A proporção recomendada é de 5 Litros de suco de limão para 100 litros de água.

Em um experimento Lima et. al (2006) conseguiu reduzir o teor de cobre das cachaças que apresentavam valores de $9 \mathrm{mg} / \mathrm{L}$ para níveis abaixo de $5 \mathrm{mg} / \mathrm{L}$ filtrando-as em carvão ativado. Porém essa técnica também reduziu os níveis de compostos orgânicos responsáveis pelo sabor e aroma característico da bebida, por isso essa técnica deve ser empregada com cautela para não depreciar a aguardente.

Portanto, é possível que a higienização inadequada e a falta de um responsável técnico para acompanhar e supervisionar a produção das cachaças possa ser um fator determinante para $40 \%$ das aguardentes apresentarem níveis elevados de cobre.

\section{CONSIDERAÇÕES FINAIS}

De acordo com os padrões de qualidade estabelecidos pela legislação brasileira, a maioria das amostras analisadas neste estudo está dentro dos parâmetros legais. Algumas amostras, que constituem a minoria das cachaças, excederam os limites permitidos para alguns parâmetros, especialmente para o Cobre que é um contaminante inorgânico muito comum em aguardentes de cana. Neste trabalho os níveis de cobre apresentaram $40 \%$ de incompatibilidade com os valores estabelecidos pela legislação. Isso se deve ao fato do processo de destilação ser feito em alambiques de cobre. Esses 
resultados demonstram a necessidade de maiores cuidados de higiene em relação aos alambiques. Porém a maior parte das amostras apresentou níveis adequados para as substâncias analisadas. Dentre elas furfural, metanol, ésteres, congêneres, além da análise da acidez volátil e do Teor alcoólico. Isso demonstra que apesar das limitações socioeconômicas, a região do Vale do Mucuri produz cachaças dentro dos padrões de qualidade exigidos nacionalmente.

\section{REFERÊNCIAS}

ALMEIDA, M. E. W. \& BARRETTO, H. H. C. - Álcoois superiores em aguardente de cana por cromatografia em fase gasosa. Rev. Inst, Adolfo Lutz, 31:117-124, 1971

BISPO, J.L.P. et al. Características físico-químicas de cachaças artesanais envelhecidas e não envelhecidas. Disponível em:

$<$ http://snida.agricultura.gov.br/binagri/bases/agb/Agb_Docs_Fonte/BR2013001346.pdf $>$. Acesso em 22 maio, 2019.

BORGES, C. A. Avaliação da Qualidade de Cachaças do Estado da Bahia. Disponível em: <http://www2.uesb.br/ppg/ppgecal/wp-content/uploads/2017/04/CARLOSALEXSANDRO.pdf $>$. Acesso em 24 maio,2019

BRAGA, M.V.F, KIYOTANI, I.B., Revista de Turismo Contemporâneo - RTC, Natal, v. 3, n. 2, p.254-275, jul./dez. 2015

BRASIL. Lei $\mathrm{N}^{\circ} 13.773$ de 19 de dezembro de 2019. Disponível em:

<https://presrepublica.jusbrasil.com.br/legislacao/661348667/lei-13773-18>. Acesso em 23 maio 2019.

BRASIL. Ministério da Agricultura Pecuária e Abastecimento. Instrução Normativa $\mathrm{N}^{\circ}$ 13. Brasília-DF, 2003. Disponível em:

$<\mathrm{http} / / / \mathrm{www}$.agricultura.gov.br/assuntos/insumos-agropecuarios/insumosagricolas/sementes-e-mudas/publicacoes-sementes-e mudas/.pdf >. Acesso em 24 maio 2019.

CARUSO, Miriam Solange Fernandes; NAGATO, Letícia Araújo Farah e ALABURDA, Janete. Benzo(a)pireno, Carbamato de Etila e Metanol em Cachaças. Quím. Nova [online]. 2010, vol.33, n.9, pp.1973-1976. ISSN 0100-4042. http://dx.doi.org/10.1590/S0100-40422010000900027.

CORNIANI, Lethícia Suzigan. Qualidade química e sensorial de cachaça envelhecida em barris de carvalho de diferentes espécies e quantidades de uso. 2017. p. 53. 
FRANÇA, Norival; FIORINI, João Evangelista. Avaliação da qualidade da cachaça artesanal produzidas no município de Passos-MG. Disponível em: <http://revista.uemg.br/index.php/praxys/article/viewFile/2206/1190>. Acesso em 20 maio, 2019.

JANZANTTI, N. S. Compostos voláteis e qualidade de sabor da cachaça. Tese (Doutorado em Ciência de Alimentos). Universidade Estadual de Campinas. Campinas, SP: [s.n.], 2004.

LAMIABLE, D.; HOIZEY, G.; MARTY, H.; VISTELLE, R. Acute methanol intoxication. EMC Toxicolie-Pathologie 2004, 1, 7.

LIMA, et al. Emprego do carvão ativado para remoção de cobre em cachaça. Disponível em: <http://www.scielo.br/scielo.php?script=sci_arttext\&pid=S0100-

40422006000200014>. Acesso em 20 maio, 2019.

LIMA, et al. III Encontro Científico e Simpósio de Educação. Disponível em: <http://www.unisalesiano.edu.br/simposio2011/publicado/artigo0145.pdf>. Acesso em 22 maio, 2019.

MACHADO, T.O.X et al. Determinação do Teor de Metanol em Cachaças Comerciais por Cromatografia Líquida de Alta Eficiência. Disponível em:

<http://www.ufrgs.br/sbctars-eventos/xxvcbcta/anais/files/313.pdf>. Acesso em 21 maio,2019.

MAPA - Ministério da Agricultura Pecuária e Abastecimento.

http://www.agricultura.gov.br/assuntos/vigilancia-agropecuaria/ivegetal/bebidasarquivos. Acesso em: 22 de maio de 2019.

MENDES FILHO, N.E et al. Caracterização de Aguardentes Artesanais de Cana-deaçúcar produzidas nas regiões de Alpercatas. Rev. Virtual Quim. 2016, n.8, pp.14211432

MINAS GERAIS, Lei nº13.949, de 11 de julho de 2001. Disponível em:< https://www.agencia.cnptia.embrapa.br/Repositorio/Cachaca_de_Minas_000fjd717w80 2wyiv809gkz51uz0mxbc.pdf>. Acesso em 23 maio 2019.

MIRANDA, M.B et al. Qualidade química de cachaças e de aguardentes brasileiras. Disponível em: <http://www.scielo.br/pdf/cta/v27n4/34.pdf>. Acesso em 19 maio, 2019.

NAGATO, Leticia Araújo Farah et al. Monitoramento da autenticidade de amostras de bebidas alcoólicas enviadas ao Instituto Adolfo Lutz em São Paulo. Ciênc. Tecnol. 
Aliment. [online]. 2001, vol.21, n.1, pp.39-42. ISSN 0101-2061.

http://dx.doi.org/10.1590/S0101-20612001000100009.

PAIVA, C.A.; GODOY, M.M. Os 300 anos da atividade canavieira em Minas Gerais. In: SEBRAE/MG. Diagnóstico da Cachaça de Minas Gerais. Belo Horizonte,2001, p. 105-108.

PARAZZI, C et al. Avaliação e caracterização dos principais compostos químicos da aguardente de cana de açúcar envelhecida em tonéis de carvalho (quercus sp.). Ciência e Tecnologia de alimentos, Campinas, v. 28, n.1, p.193-199, jan/mar. 2008.

PELLENZ, J. M. et al. Avaliação da qualidade de cachaças produzidas na região norte de Mato Grosso. Disponível em:

<http://www.seasinop.com.br/revista/index.php?journal=SEA\&page=article\&op=view \&path\%5B\%5D=322>. Acesso em 15 maio, 2019.

PINTO, F.G, ROCHA, S.S et al. Determinação de cobre e zinco em cachaça por espectrometria de absorção atômica com chama usando calibração por ajuste de matriz. Disponível em: 〈http://www.ufjf.br/baccan/files/2011/05/Zinco_cachaca_art031.pdf>. Acesso em 22 maio, 2019.

SILVA, et al. Cachaça De Minas E Desenvolvimento Rural: Uma Análise Do Cooperativismo Como Impulso Para O Agronegócio, 2013. Disponível em: $<$ https://www.agencia.cnptia.embrapa.br/Repositorio/Cachaca_de_Minas_000fjd717w8 02wyiv809gkz51uz0mxbc.pdf>. Acesso em 20 maio,2019

SILVA, M. J. Percepção da qualidade de cachaça artesanal pelo consumidor: notoriedade das marcas versus aceitação sensorial. Dissertação (Mestrado em Tecnologia Agroalimentar). Universidade Federal da Paraíba. - Bananeiras, PB, 2011. 99f.:il.

SOUZA, Leandro Marelli de et al. Teores de compostos orgânicos em cachaças produzidas na região norte fluminense - RJ. Quím. Nova [online]. 2009, vol.32, n.9, pp.2304-2309.

VILELA, A.F. Estudo da Adequação de Critérios de Boas Práticas de Fabricação na Avaliação de Fábricas de Cachaça de Alambique. Disponível em: <http://www.pergamum.univale.br/pergamum/tcc/Estudodaadequacaodecriteriosdeboaspratic asdefabricacaonaavaliacaodefabricasdecachacadealambique.pdf $>$. Acesso em 20 maio,2019

VILELA, Fernando José; CARDOSO, Maria das Graças; MASSON, José e ANJOS, Jeancarlo Pereira dos. Determinação das composições físico-químicas de cachaças do sul de minas gerais e de suas misturas. Ciênc. agrotec. [online]. 2007, vol.31, n.4, pp.1089-1094. ISSN 1413-7054. http://dx.doi.org/10.1590/S141370542007000400022 . 
ZACARONI, Lidiany Mendonça et al. Caracterização e quantificação de contaminantes em aguardentes de cana. 2011, vol.34, n.2, pp.320-324. 